\title{
2. Structural Features of Alphafetoprotein in Relation to its Function and Diagnostic Application*
}

\author{
By
}

\author{
Erkki Ruoslahti**
}

\section{Introduction}

Gene products with a normal expression restricted to the embryonal and fetal periods are frequently reexpressed in tumors. To recognize this dual expression, such components are grouped under the heading of carcinoembryonal, carcinofetal, or oncodevelopmental gene products. Alphafetoprotein (AFP) is one of the most thoroughly characterized oncodevelopmental proteins. A vast amount of work has been done since this protein was first observed by Bergstrand and Czar (1956) twenty or so years ago and brought into the limelight by the observation of Abelev and coworkers (Abelev et al., 1963) that AFP was associated with liver cancer. In the following, I will summarize the salient features of the molecular characteristics and functional properties of AFP. The structure and function of alphafetoprotein (AFP) will have to be known more thoroughly than is the case today if we are to achieve full understanding of the expression of this protein during fetal development and in cancer.

\section{Isolation of AFP}

The availability of purified AFP from several species has been the basis of the studies that have led to the present understanding of the characteristics and expression of this protein.

The relative abundance of AFP in the fetus and in occasional tumor sera has made its purification a relatively simple task. Human AFP was first isolated from AFP-anti AFP immunoprecipitates by gel filtration at low pH (Nishi, 1970 ; Ruoslahti and Seppälä, 1971). More recently immunoadsorbents have been utilized to purify AFP.

A recent development in this area is the use of immunochromatography on antibodies with very low affinity (Ruoslahti, 1978). This method makes use of the fact that AFP is present in all mammalian species (and in chicken) as immunologically and chemically related, but not identical, molecules.

Antibodies against AFP of one species have a lower affinity to AFP from another species than they have to the AFP used for immunization. Such crossreactive antibodies can be utilized to prepare immunoadsorbents possessing a very low affinity. A major part of the AFP elutes from such columns with phosphate buffered saline, and the rest can be eluted as a sharp peak with a small quantity of 4 or $6 \mathrm{~m}$ urea. The elution of AFP with the initial column buffer has made it possible to prepare pure AFP which has not been subjected to the chaotropic elution buffers usually employed in affinity chromatography. The ease of elution of the bound AFP from the absorbent column has allowed purification of AFP in gram quantities. Monoclonal antibodies that have recently become available (see below) make it possible

* $\alpha$-フェトプロティンの構造と機能拉よびその診断的応用.

** La Jolla Cancer Research Foúndation, 
to prepare improved affinity colums with homogeneous affinity antibodies.

The availability of large quantities of AFP has greatly facilitated our studies on its structure-function relationships.

\section{Structure-Function Relationships in AFP}

Protein moiety of AFP is a glycoprotein with a molecular weight close to 70,000 and with about $4 \%$ carbohydrate (Nishi, 1970 ; Ruoslahti and Seppälä, 1971). About 15\% of the amino acid sequence of AFP is known from N-terminal sequencing of the whole molecule and some of its cyanogen bromide frag. ments (Ruoslahti et al., 1974; Ruoslahti and Terry, 1976). About $50 \%$ homology between the sequence of two AFP fragments and the region of albumin residues 200-260 was found. The $\mathrm{N}$-terminal sequence and sequences of some cyanogen bromide fragments from bovine AFP (unpublished results) do not show homology with albumin. It seems that AFP and albumin are homologous only in certain regions of the molecule. It is interesting that the area where homology is found (albumin residues 200-290) includes the site in albumin to which bilirubin binds (Jacobsen, 1978). AFP also binds bilirubin (see below). Further support for the structural similarity of AFP and albumin comes from the immunological crossreactivity which these two proteins show when they are unfolded by reduction of the disulfide bonds followed by carboxamidomethylation (Ruoslahti and Engvall, 1976). A schematic presentation of the structural relationship of AFP and albumin is shown in Fig. 1.

The structural similarities of AFP and albumin (Ruoslahti and Terry, 1976) have prompted us and others to look for similarities in the functional properties of AFP and albumin. The main known functions of serum albumin are the maintenance of the intravascular osmotic pressure and transport of various low molecular weight substances in plasma (see Peters, 1975 and papers cited therein). In light of recent results from several laboratories, it seems that many of the binding and transporting functions of albumin are shared by AFP.

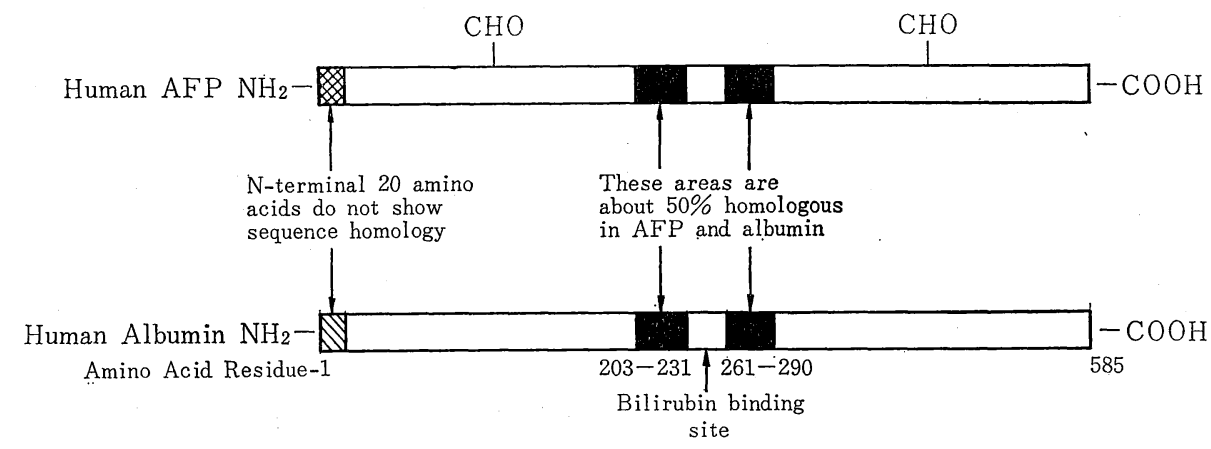

Fig. 1. A schematic presentation of the essential structural features of AFP as compared to albumin.

The complete amino acid sequence of albumin is known (Brown, 1976). The shaded areas represent the parts of the AFP molecule where sequence information is available. The N-terminal sequences of the two proteins are not homologous, but two fragments of AFP have been found to be homologous with the albumin sequences between residues 203-231 and 261-290, respectively (Ruoslahti and Terry, 1976)... The remaining parts of the AFP polypeptide have not been sequenced. Note that the number and position of the carbohydrate chains is not known and that they have been placed arbitrarily. 
It is well established that rat and mouse AFPs bind estrogens with a high affinity (reviewed by Nunez et al., 1976). The claims that a small subfraction of human AFP binds estrogen have not been substantiated in more recent studies (see Ruoslahti and Seppälä, 1979). Since the binding of estrogens by AFP has been found only in some of the rodent species and AFP has been shown to bind other small molecular weight substances, the estrogen binding may be a specialized expression of more general binding properties of AFP.

Human and bovine AFP have affinity to bilirubin (Ruoslahti et al., 1978 ; Aoyagi et al., 1978). The spectral properties of bilirubin are altered in the presence of albumin and bovine or human AFP. While albumin causes a shift of the absorption maximum toward a higher wavelength, bovine AFP gives a change in the opposite direction. Both increase the absorption by bilirubin. These changes have made it possible to study the characteristics of the interaction between AFP and bilirubin. AFP has one binding site with an association constant somewhat lower than that of albumin.

Parmelee et al. (1978) recently found that purified human AFP contains fatty acids. They found an average of $2.4 \mathrm{~mol}$ of predominantly polyunsaturated fatty acids associated per mole of AFP. Similar fatty acids were found to be associated with albumin isolated from fetal sources, but in lesser amounts.

We have recently demonstrated fatty acid binding by bovine AFP. Like human AFP, bovine AFP seems to preferentially bind long chain, polyunsaturated fatty acids (Table 1). In addition to bilirubin and fatty acids, several other substances that bind to albumin also show affinity to AFP (Table 2, see Ruoslahti, 1978).

While the exact functional role of AFP remains to be elucidated, the evolutionary preservation of AFP, evidenced by the fact that AFP has been found to be present during fetal life in all species studied, suggests that one or several of the functional properties of AFP are such that albumin cannot substitute

Table 1. Ratios of short and long chain fatty acids bounds to AFP and albumin.*

\begin{tabular}{l|c|c|c|c|c}
\hline \hline & $\begin{array}{c}\text { Total of C14-C18 } \\
\text { mol fatty } \\
\text { acid/mol protein }\end{array}$ & $\begin{array}{c}\text { \% of Total } \\
\text { fatty acid }\end{array}$ & $\begin{array}{c}\text { Total of C20-C22 } \\
\text { mol fatty } \\
\text { acid/mol protein }\end{array}$ & $\begin{array}{c}\text { \% of Total } \\
\text { fatty acid }\end{array}$ & $\begin{array}{c}\text { Ratio of } \\
\text { C20:4/C18:2 }\end{array}$ \\
\hline BAFP & 1.412 & 55 & 1.170 & 45 & 2.32 \\
Fetal BSA & 1.499 & 95 & 0.073 & 5 & 0.54 \\
Adult BSA & 0.885 & 100 & - & - & 0.00 \\
\hline
\end{tabular}

* Estes, T., Ruoslahti, E., DeGroot, J., and Holden, J. T., unpublished results.

Table 2. Binding of small molecular weight ligands by AFP.*

\begin{tabular}{|c|c|c|c|}
\hline Substance & $\begin{array}{l}\text { Affinity as compared to } \\
\text { that of albumin }\end{array}$ & $\begin{array}{l}\text { Number of } \\
\text { binding sites }\end{array}$ & Species \\
\hline Fatty acids & $\begin{array}{l}\text { Similar, apparently higher for } \\
\text { long chain, polyunsaturated } \\
\text { fatty acids }\end{array}$ & & Human, bovine, porcine \\
\hline Bilirubin & Somewhat lower & 1 & Human, bovine, rat \\
\hline Copper (II) & Not measured & & Human \\
\hline Deoxycholate & Lower & 20 & Human \\
\hline Retinoic acid & Lower & 1 & Human, bovine, mouse \\
\hline Estradiol & Much higher & 1 & Rat, mouse(but not other species) \\
\hline
\end{tabular}

* For references, see text and Ruoslahti, 1978. 
for it during fetal life. It is possible that AFP is involved in the fetal metabolism of fatty acids, especially the long chain polyunsaturated ones. Since these fatty acids are precursors of biologically ighly active compounds such as prostaglandins, AFP may turn out to play a very significant functional role in the fetus.

\section{Carbohydrate Moiety of AFP}

Unlike albumin, AFP contains carbohydrate. The general composition of the carbohydrate moiety is usual, but it does exhibit interesting and potentially important microheterogeneity. It was initially observed that rat AFP can be divided into two subfractions, one reactive with the lectin concanavalin A (con A), and the other nonreactive (Smith and Kelleher, 1973). This has recently been found to be the case with human AFP also (Ruoslahti et al., 1978). The two main fetal sources of AFP seem to be responsible for the production of the variants, at least in humans and mice. The con A nonreactive variant originates mainly from the yolk sac, and the con A reactive one, from the liver (Ruoslahti and Adamson, 1978). Promising results with respect to the utility of the variants in the diagnosis of some fetal malformations have already been presented (Smith et al., 1979 ; Ruoslahti et al., 1979). Preliminary results have suggested that the con A nonreactive variant can be elevated in the AFP produced by liver cancer (Ruoslahti et al., 1978; and unpublished). This raises the possibility that it may be possible to differentiate the AFP associated with liver regeneration from that produced by a liver cancer. This would be most useful, and studies to explore this possibility are in progress.

In view of the emerging utility of the con A variants in the diagnostic use of the AFP assay, we have initiated attempts to develop antibodies specific for the variants. This would allow more practical tests for the variants than is possible with current methods. The con A variants are immunolocially identical when tested with usual anti-AFP reagents.

The hybridoma technique developed by Köhler and Milstein (1975) allows production of homogeneous antibody in malignant cell hybrids of antibodyproducing lymphocytes and myeloma cells. Since monoclonal antibodies react with a single determinant in a given macromolecule, these reagents also offer new possibilities for specific detection of molecular variants such as the con A variants. The fact that large quantities of antibody, which are homogeneous with respect to their molecular and antigen-binding properties can be obtained, also offers some obvious advantages for the usual AFP immunoassays.

We have prepared monoclonal antibodies to human alphafetoprotein (AFP) using hybrids of mouse myeloma cells and spleen lymphocytes from mice immunized with AFP. These antibodies show binding to insolubilized AFP in high titers in enzyme-linked immunosorbent assay (ELISA) and radioimmunoassay. The binding is inhibitable by soluble AFP (Fig. 2), and assays set up with the monoclonal antibodies give results similar to those obtained with conventional antibodies when various AFP-containing body fluids are tested (Uotila et al., 1979). Such antibodies may, by virtue of their homogeneity, allow a more precise standardization of the AFP assay than has been previously possible. The monoclonal antibodies we have prepared so far have reacted equally well with both con A variants.

Some of the monoclonal antibodies we have prepared have been poorly inhibitable with AFP, indicating that they have a low affinity to AFP. Immunoadsorbent columns prepared using such antibodies have allowed isolation of AFP under conditions where a large fraction of AFP is eluted with a relatively mild treatment of the column. Since large quantities of such antibodies can easily be prepared (we have had up to $5 \mathrm{mg} / \mathrm{ml}$ of anti-AFP in ascites of mice bearing the hybridomas), the low affinity of monoclonal antibodies may be useful in immunological purification of AFP.

In conclusion, AFP and albumin seem to be related both structurally and as regards their function and probably have a common ancestor. However, the structural data available on AFP are fragmentary, 


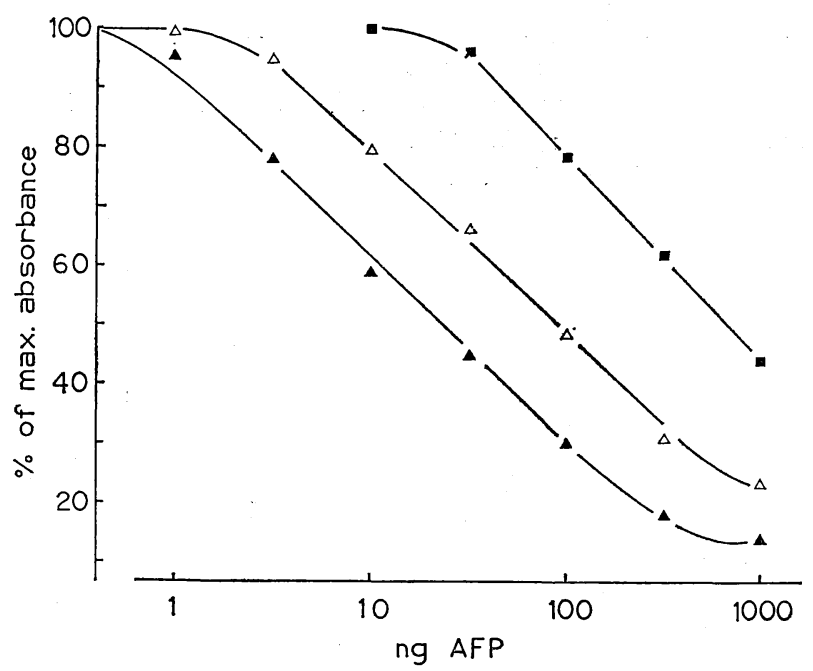

Fig. 2. Inhibition by unlabeled AFP of binding of antibodies in mouse anti-AFP $(\triangle)$, and monoclonal antibodies with high (A) and low ( affinity to microtiter wells coated with AFP in ELISA assay.

and the binding of various ligands to AFP has, with the possible exception of fatty acids, been with a lower affinity than that between albumin and the same ligand. More structural work should be done, and further ligands tested for binding to AFP. Monoclonal antibodies may become a useful tool in delineating the structural features of AFP and may also provide useful reagents for the assay of AFP and its molecular variants as well as for their purification.

\section{Acknowledgment}

This work was supported by grant CA 27460 from the National Cancer Institute, DHHS.

\section{References}

1) Abelev, G. I. et al. : Transplantation, 1:174, 1963.

2) Aoyagi, Y. et al. : Cancer Res., $38: 3483,1978$.

3) Bergstrand, C.G. and Czar, B. : Scand. J. Clin. Lab. Invest., 8 : 174, 1956.

4) Brown, J.R. : Fed. Proc., $35: 2141,1976$.

5) Jacobsen, C. : Biochem. J., 171: 453, 1978.

6) Nishi, S. : Cancer Res., $30: 2507,1970$.

7) Nunez, E. A. et al. : Chapter B, in Protides of the Biological Fluids, 24 th Colloquim, Bruges, 1975, H. Peeters (ed.), Pergamon Press, Oxford, 1976, p. 255.

8 ) Peters, T., Jr. : in the Plasma Proteins, Vol.1, 2 nd ed.(Putnam, F.W. Ed.), Academic Press, New York, 1975, p. 133.

9) Ruoslahti, E. : in Carcino-Embryonic Proteins, Vol. I (Lehmann, F. -G. Ed.), Elsevier/North Holland Biomedical Press, Amsterdam, 1979, p. 154.

10) Ruoslahti, E. and Adamson, E. : Biochem. Biophys. Res. Commun., 85 : 1622, 1978.

11) Ruoslahti, E. and Engvall, E. : Proc. Natl. Acad. Sci. U.S. A., 73 : 4641, 1976.

12) Ruoslahti, E. and Seppälä, M. : Int. J. Cancer, $7: 218,1971$.

13) Ruoslahti, E. and Seppälä, M. : Int. J. Cancer, 8 : 374, 1971.

14) Ruoslahti, E. and Seppälä, M. : Adv. Cancer Res., 29 : 275, 1979.

15) Ruoslahti, E. and Terry, W.D. : Nature, $260: 804,1976$.

16) Ruoslahti, E. et al. : The Johns Hopkins Medical Jounal, Suppl., $3: 249$, 1974.

17) Ruoslahti, E. et al. : Int. J. Cancer, 22:515, 1978. 
（100）生物物理化学

18) Ruoslahti, E. et al. : Biochim. Biophys. Acta, $578: 511,1979$.

19) Ruoslahti, E. et al. : Brit. Med. J., 2 : 768, 1979.

20) Smith, C. J. and Kelleher, P. C. : Biochim. Biophys. Acta, $317: 231,1973$.

21) Smith, C. J. et al. : Brit. Med. J., 1: 920, 1979.

22) Uotila, M. et al. : Submitted for publication. 